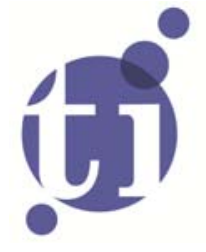

\title{
A Target-Oriented Data Envelopment Analysis for Energy-Environment Efficiency Improvement in Japan
}

Soushi Suzukir

Peter Nijkamp

Piet Rietveld²

1 Hokkai-Gakuen University, Japan;

2 Faculty of Economics and Business Administration, VU University Amsterdam, Tinbergen Institute, The Netherlands. 
Tinbergen Institute is the graduate school and research institute in economics of Erasmus University Rotterdam, the University of Amsterdam and VU University Amsterdam.

More TI discussion papers can be downloaded at http://www.tinbergen.nl

Tinbergen Institute has two locations:

Tinbergen Institute Amsterdam

Gustav Mahlerplein 117

1082 MS Amsterdam

The Netherlands

Tel.: +31(0)205251600

Tinbergen Institute Rotterdam

Burg. Oudlaan 50

3062 PA Rotterdam

The Netherlands

Tel.: +31(0)10 4088900

Fax: $+31(0) 104089031$

Duisenberg school of finance is a collaboration of the Dutch financial sector and universities, with the ambition to support innovative research and offer top quality academic education in core areas of finance.

DSF research papers can be downloaded at: http://www.dsf.nl/

Duisenberg school of finance

Gustav Mahlerplein 117

1082 MS Amsterdam

The Netherlands

Tel.: +31(0)20 5258579 


\title{
ATarget-Oriented Data Envelopment Analysis for Energy-Environment Efficiency Improvement in Japan
}

\author{
Soushi Suzuki ${ }^{\mathrm{a}}$ \\ PeterNijkamp $^{b^{*}}$ \\ Piet Rietveld

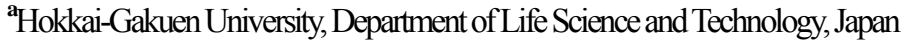 \\ ${ }^{b}$ VU University Amsterdam, Department of Spatial Economics, and Tinbergen Institute, The Netherlands \\ *corresponding author, p.nijkamp@vu.nl, phone+31 20598 6090, fax +31 205986004
}

\begin{abstract}
This paper offers a quantitative contribution to energy-environment policy in Japan in the aftermath of the Fukushima nuclear power accident. Since then, nuclear power energy supply has almost entirely been banned.There is no clear-cut direction for energy policy, as each option involves costs and $\mathrm{CO}_{2}$ consequences. A balanced energy-environment policy is difficult to achieve and there is an urgent need for a comprehensive efficiency and performance analysis of the Japanese energy sector.

This paper presents a newly developed adjusted DEA model, emerging from a blend of the Euclidian Distance Minimization EDM method and the Target-Oriented (TO) approach based on a Super-Efficiency model, for generating an appropriate efficiency-improving projection model. The TO approach specifies a TargetEfficiency Score (TES) for inefficient DMUs. This approach can compute an input reduction value and an output increase value in order to achieve a higher TES.

This model will be applied to an efficiency analysis of the energy-environment interface for ten regions in Japan. The focus is on two input cost criteria (viz. expenditures and $\mathrm{CO}_{2}$ emission) and two output performance criteria (viz. electricity generation and regional $\mathrm{CO}_{2}$ absorption). A comparative performance analysis of the ten Japan regions under consideration will be pursued.
\end{abstract}

Keywords: Data Envelopment Analysis (DEA), Euclidean Distance Minimisation (EDM), Target-Oriented (TO), Energy-Environment efficiency 


\section{Introduction}

Japan is faced with the 'Fukushima' problem, meaning that one single nuclear accident has led to a drastic electrical power shortage. Japan had 54 nuclear plants but almost all have stopped generating owing to the strong backlash of public opinion. The ten regional electrical companies in Japan (Hokkaido, Tohoku, Tokyo, Chubu, Hokuriku, Kansai, Chugoku, Shikoku, Kyushu and Okinawa, see Figure 1) have permission to increase thermal power generation based on coal, oil and LNG (liquefied natural gas) in order to compensate for the shortfall following the accident. This creates the problem of an increase in "electricity cost" and " $\mathrm{CO} 2$ emission", which is then related to a non-balanced "Energy-Environment" policy. Although it is difficult at this stage, it is necessary to make an effort to achieve a more efficient "Energy-Environment" policy in Japan, even though Japan has decided to withdraw from the Kyoto protocol.

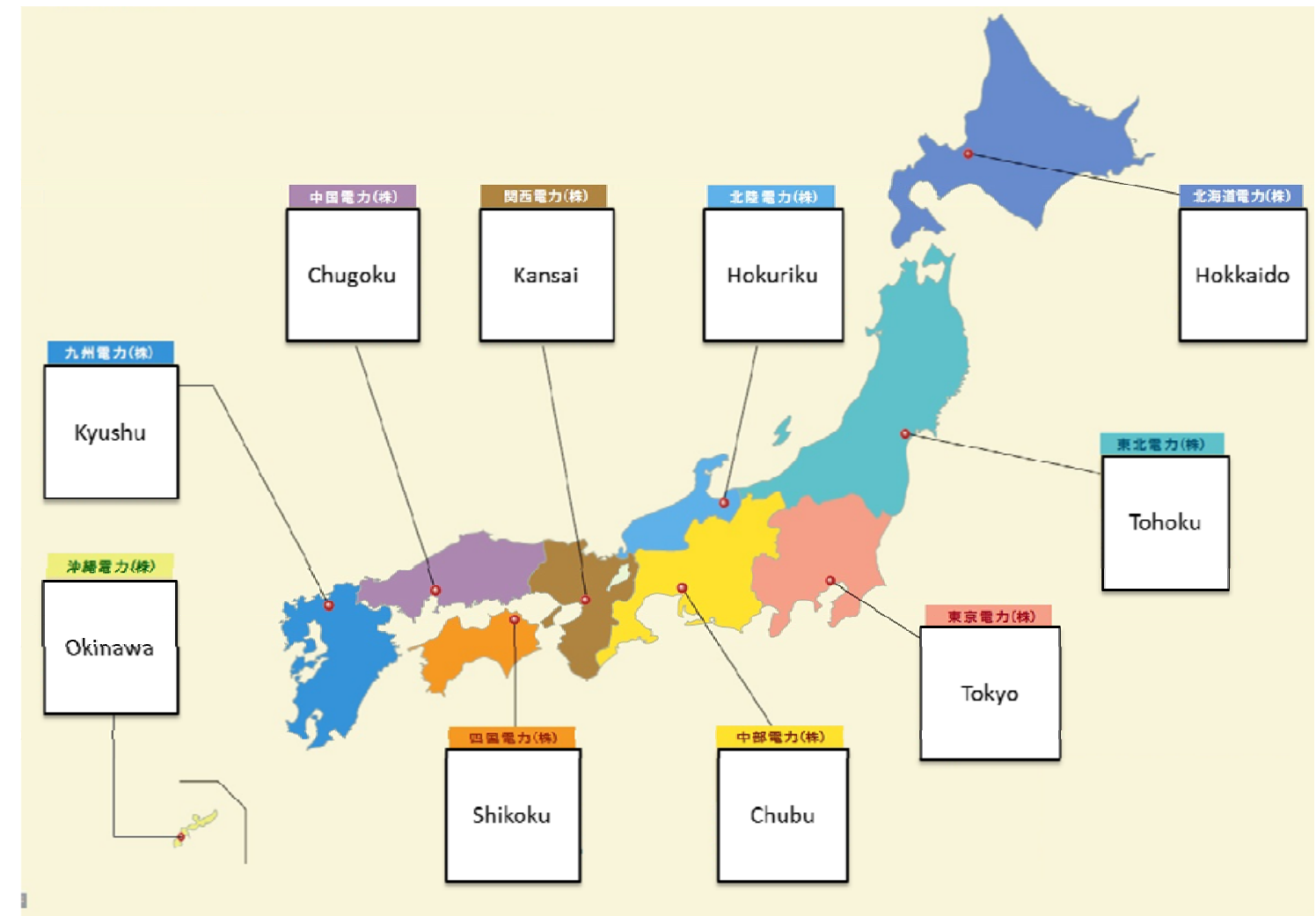

Figure 1 Ten electrical companies in JAPAN

A standard tool by which to judge efficiency is Data Envelopment Analysis (DEA), proposed by Charnes, Cooper and Rhodes (1978) (CCR hereafter, see appendix A1). This has become an established assessment method in industrial organization. Seiford (2005) mentions some 2800 published articles on DEA. This large number of studies shows that comparative efficiency analysis has become an important research issue.

DEA was developed to analyse the relative efficiency of a decision-making unit (DMU), by constructing a piecewise linear production frontier and projecting the performance of each DMU onto that frontier. ADMU that is located on the frontier is efficient, whereas a DMU that is not on the frontier is inefficient. An inefficient DMU can become efficient by reducing its inputs, or by increasing its outputs. In the standard DEA approach, this is achieved by a uniform reduction in all inputs (or a uniform increase in all outputs). However, in principle, there are an infinite number of possible improvements that could be implemented in order to reach the efficient frontier and hence, there are many solutions should a DMU plan to enhance its efficiency.

In the last few decades, the existence of many possible efficiency improvement solutions has prompted a rich 
literature on the methodological integration of Multiple Objective Linear Programming (MOLP) and the DEA models. The first contribution was by Golany (1988) who proposed an interactive MOLP procedure, which aimed at generating a set of efficient points for a DMU. This model allows a decision maker to select the preferred set of output levels, given the input levels. Next, Thanassoulis and Dyson (1992) developed adjusted models, which can be used to estimate alternative input and output levels, in order to render relatively inefficient DMUs more efficient. These models are able to incorporate preferences for a potential improvement of individual input and output levels. The resulting target levels reflect the user's relative preference over altemative paths to efficiency. Joro et al. (1998) demonstrated the analytical similarity between a DEA model and a Reference Point Model in a MOLP formulation from a mathematical viewpoint. In addition, the Reference Point Model provides suggestions, which make it possible to search freely on the efficient frontier for good solutions, or for the most-preferred solution (MPS) based on the decision-maker's preference structure. Furthermore, Halme et al. (1999) developed a Value Efficiency Analysis (VEA), which included the decision-maker's preference information in a DEA model. The foundation of VEA originates from the Reference Point Model in a MOLP context. Here the decision maker identifies the MPS, such that each DMU could be evaluated by means of the assumed value function based on the MPS approach. A further development of this approach was made by Korhonen and Siljamäki (2002) who dealt with several practical aspects related to the use of a VEA. In addition, Korhonen et al. (2003) developed a multiple objective approach, which allows for changes within the time frame. Lins et al. (2004) proposed two multiobjective approaches that determine the basis for the incorporation of a posteriori preference information. The first of these models is called Multiple Objective Ratio Optimisation (MORO), which optimises the ratios between the observed and the target inputs (or outputs) of a DMU. The second model is called Multiple Objective Target Optimisation (MOTO), which directly optimises the target values. Washio et al. (2012) suggested four types of improvements for making inefficient DMUs efficient in the CCR, by introducing a decision-maker's policy model with the minimal change of input and output values. Finally, Yang et al. (2013) utilise DEA and Nash bargaining game (NBG) theory to improve inefficient banks, in order to: (i) make an inefficient bank Paretooptimal for multiple perspectives, which could avoid being discontent with some particular perspectives; and (ii) change its attributes and provide various improvement schemes for decision makers. Finally, Suzuki et al. (2010) proposed a Euclidean Distance Minimisation (EDM) model that is based on a generalised distance function and serves to improve the performance of a DMU by identifying the most appropriate movement towards the efficiency frontier surface. The EDM model is able to calculate either an optimal input reduction value or an output increase value in order to reach an efficiency score of 1.000, even though in reality this might be hard to achieve for low-efficiency DMUs.

The aim of this paper is to present and apply a newly developed adjusted DEA model, emerging from a blend of EDM and the Target Oriented (TO) approach based on the Super-efficiency model (Andersen and Petersen (1993), see Appendix A2), in order to generate a more appropriate efficiency-improving projection model. The TO approach specifies a Target Efficiency Score (TES) for each DMU. This approach can compute an input reduction value and an output increase value in order to achieve a TES for the efficiency improvement.

The above-mentioned TS-EDM model is applied to an efficiency analysis of the "Energy-Environment" sector for the ten regions related to the management zones of the ten electrical power companies in Japan.

The paper is organised as follows. Section 2 introduces our EDM methodology and Section 3 proposes the new model, which is a TO model in the framework of an EDM model. Section 4 then presents an application of the methodology to an efficiency analysis of the "Energy-Environment" of the ten regions in Japan. Finally, Section 5 draws some conclusions.

\section{The Eudidean Distance Minimisation (EDM)Approach}

An efficiency improvement solution in the original DEA model (abbreviated hereafter as the CCR-input model, see Appendix A1) requires that the input values are reduced radially by a uniform ratio $\theta^{*}\left(\theta^{*}=\mathrm{OD}\right.$ '/OD in Figure 
A1).

The $\left(v, u^{*}\right)$ values obtained as an optimal solution for formula (A.1) result in a set of optimal weights for $\mathrm{DMU}_{0}$. Hence, $\left(v^{*}, u^{*}\right)$ is the set of most favourable weights for $\mathrm{DMU}_{0}$, in the sense of maximising the ratio scale. $\nu_{m}{ }^{*}$ is the optimal weight for the input item $m$ and its magnitude expresses how much in relative terms the item is contributing to efficiency. Similarly, $u_{s}^{*}$ does the same for the output item $s$. These values show not only which items contribute to the performance of $\mathrm{DMU}_{\mathrm{o}}$ but also the extent to which they do so. In other words, it is possible to express the distance frictions (or alternatively, the potential increases) in improvement projections.

We use the optimal weights $u_{s}{ }^{*}$ and $v_{m}{ }^{*}$ from (A.1) and then describe the efficiency improvement projection model. A visual presentation of this approach (EDM projection) is given in Figures 2 and 3.
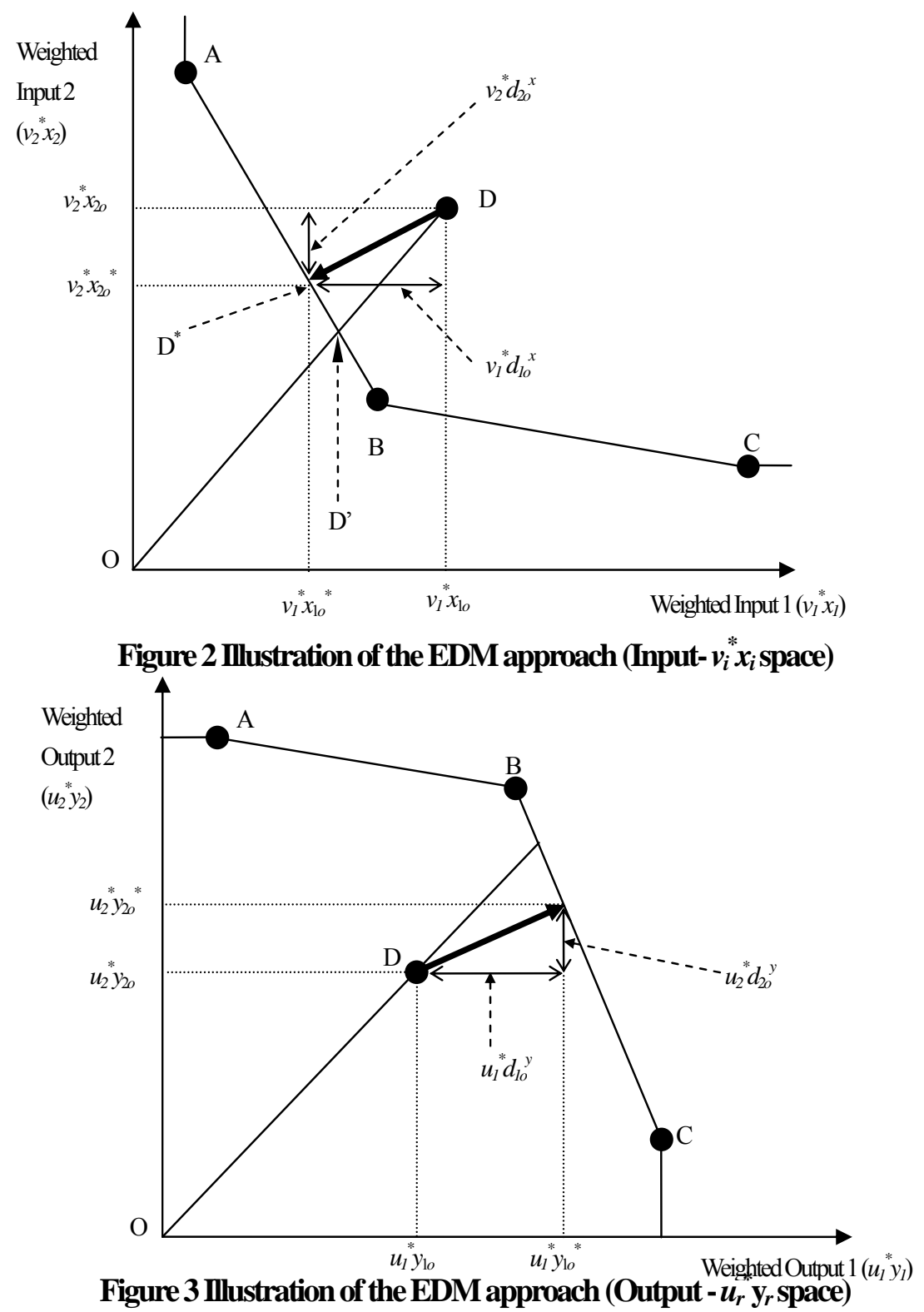

In this approach, a generalised distance indicator is employed to assist a DMU to improve its efficiency by a movement towards the efficiency frontier surface. Of course, the direction of efficiency improvement depends on the input/output data characteristics of the DMU. It is now appropriate to define the projection functions for the 
minimisation of distance by using a Euclidean distance in weighted space. As mentioned, a suitable form of multidimensional projection functions that serves to improve efficiency is given by a Multiple Objective Quadratic Programming (MOQP) model, which aims to minimise the aggregated input reductions, as well as the aggregated output increases. Thus, the EDM approach can generate a new contribution to efficiency enhancement problems in decision analysis by employing a weighted Euclidean projection function and at the same time, it might address both input reduction and output increase. Here, we only briefly describe the various steps.

First, the distance function $\mathrm{Fr}^{x}$ and $\mathrm{Fr}^{y}$ is specified by means of (2.1) and (2.2), which are defined by the Euclidean distance shown in Figures 2 and 3. Next, the following MOQP is solved by using $d_{m o}^{x}$ (a reduction of distance for $x_{i o}$ ) and $d_{s o}^{y}$ (an increase of distance for $y_{\mathrm{so}}$ ) as variables:

$$
\begin{aligned}
& \min \mathrm{Fr}^{x}=\sqrt{\sum_{m}\left(v_{m}^{*} x_{m o}-v_{m}^{*} d_{m o}^{x}\right)^{2}} \\
& \min F r^{y}=\sqrt{\sum_{s}\left(u_{s}^{*} y_{s o}-u_{s}^{*} d_{s o}^{y}\right)^{2}} \\
& \text { s.t. } \sum_{m} v_{m}^{*}\left(x_{m o}-d_{m o}^{x}\right)=\frac{2 \theta^{*}}{1+\theta^{*}} \\
& \sum_{s} u_{s}^{*}\left(y_{s o}+d_{s o}^{y}\right)=\frac{2 \theta^{*}}{1+\theta^{*}} \\
& x_{m o}-d_{m o}^{x} \geq 0 \\
& d_{m o}^{x} \geq 0 \\
& d_{s o}^{y} \geq 0
\end{aligned}
$$

where $x_{m o}$ is the amount of input item $m$ for any arbitrary inefficient $\mathrm{DMU}_{\mathrm{o}}$ and $y_{s o}$ is the amount of output item $s$ for any arbitrary inefficient $\mathrm{DMU}_{\mathrm{o}}$. The constraint functions (2.3) and (2.4) refer to the target values of input reduction and output augmentation. The faimess in the distribution of contributions from the input and output side to achieve efficiency is established as follows. The total efficiency gap to be covered by inputs and outputs is (1$\left.\theta^{*}\right)$. The input and the output side contribute according to their initial levels 1 and $\theta^{*}$, implying shares $\theta^{*} /\left(1+\theta^{*}\right)$ and $1 /\left(1+\theta^{*}\right)$ in the improvement contribution. Clearly, the contributions from both sides equal $\left(1-\theta^{*}\right)\left[\theta^{*} /\left(1+\theta^{*}\right)\right]$ and $\left(1-\theta^{*}\right)\left[1 /\left(1+\theta^{*}\right)\right]$.

Hence, we find for the input reduction target and the output augmentation targets:

$$
\begin{aligned}
& \text { Input reduction target: } \sum_{m} v_{m}^{*}\left(x_{m o}-d_{m o}^{x}\right)=1-\left(1-\theta^{*}\right) \times \frac{1}{\left(1+\theta^{*}\right)}=\frac{2 \theta^{*}}{1+\theta^{*}} . \\
& \text { Output augmentation target: } \sum_{s} u_{s}^{*}\left(y_{s o}+d_{s o}^{y}\right)=\theta^{*}+\left(1-\theta^{*}\right) \times \frac{\theta^{*}}{\left(1+\theta^{*}\right)}=\frac{2 \theta^{*}}{1+\theta^{*}} .
\end{aligned}
$$


An illustration of the above situation is presented in Figure 4.

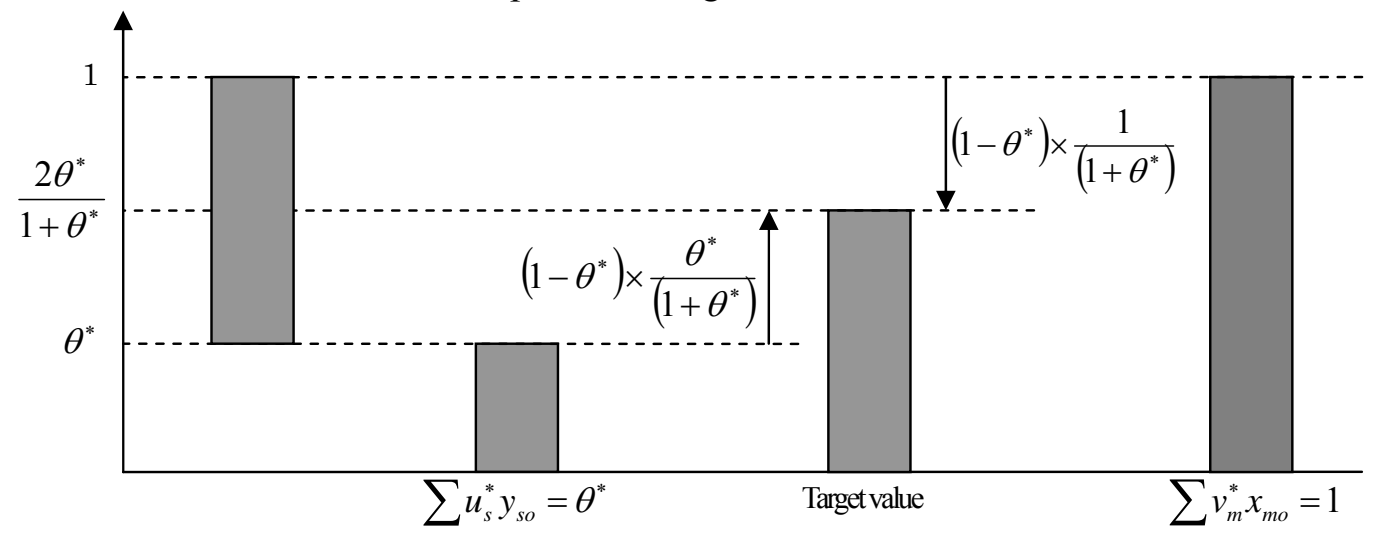

Figure 4 EDM model with an illustration of a balanced contribution of inputs and outputs to close the efficiency gap

It is now possible to determine each optimal distance $d_{m o}^{x *}$ and $d_{s o}^{y *}$ by using the MOQP model (2.1)-(2.7). The distance minimisation solution for an inefficient $\mathrm{DMU}_{\mathrm{o}}$ can be expressed by means of formulas (2.10) and (2.11):

$$
\begin{aligned}
& x_{m o}^{*}=x_{m o}-d_{m o}^{x^{*}} ; \\
& y_{s o}^{*}=y_{s o}+d_{s o}^{y *} .
\end{aligned}
$$

By means of the EDM model, it is possible to present a new efficiency-improvement solution based on the standard CCR projection. This means an increase in new options for efficiency-improvement solutions in DEA. The main advantage of the EDM model is that it yields an outcome on the efficient frontier that is as close as possible to the DMU's input and output profile (see Figure 5).

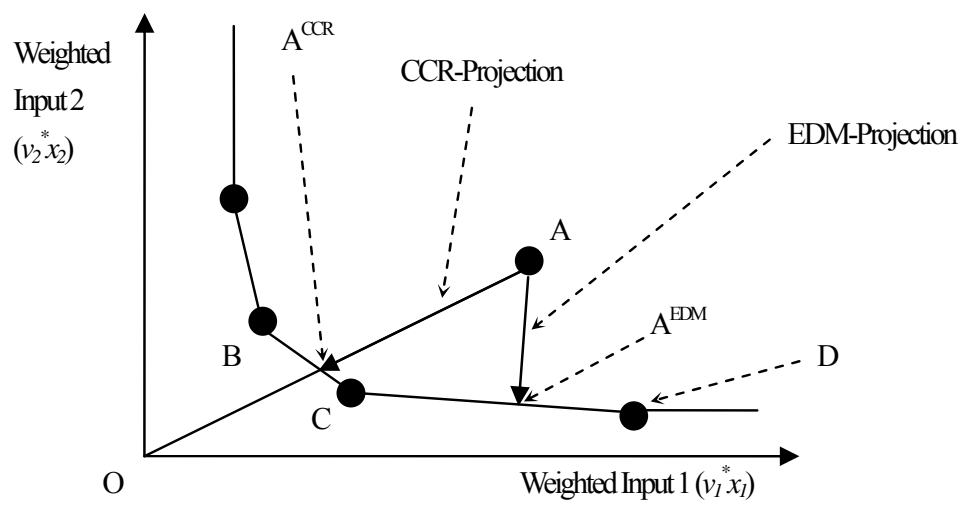

Figure 5 Degree of improvement of the EDM and the CCR projection in weighted input space

\section{A Proposed Target Oriented-EDM model}


The above-mentioned EDM model is able to calculate an optimal input reduction value and an output increase value in order to reach an efficiency score of 1.000 , even though in reality this might be hard to achieve for lowefficiency DMUs. Therefore we consider a method that allows reference points that remain below the efficiency frontier. On the other hand, DMUS that are close to (or exactly on) the efficient frontier might search for a reference point for a further improvement of their efficiency.

This paper proposes a new Target Oriented (TO) approach in the framework of the EDM model based on the Super-efficiency model (Andersen and Petersen (1993), see Appendix A2), which is based on the CCR-I model. The TO approach comprises the following steps:

Step1. Target Efficiency Score (TES) for $\mathrm{DMU}_{\mathrm{o}}$ (hereafter $\mathrm{TES}_{0}$ ) is set arbitrarily by the decision or policy maker. Improving projections are categorised in 3 types depending on the score of the TES as follows: $\theta^{*}<\mathrm{TES}_{0}<1.000$; Non-Attainment EDM projection (it does not reach the efficiency frontier). This makes sense for DMUs that are -far- below the efficiency frontier.

$\mathrm{TES}_{0}=1.000$; Normal EDM projection (it just reaches the efficiency frontier).

$\mathrm{TES}_{0}>1.000$; Super-Efficient EDM projection (it is beyond the efficiency frontier). This makes sense for DMUs that are already on the efficiency frontier

Step2. Solve $T E S_{0}=\frac{\theta^{*}+M P_{0}\left(1-\theta^{*}\right) \times \frac{\theta^{*}}{\left(1+\theta^{*}\right)}}{1-M P_{0}\left(1-\theta^{*}\right) \times \frac{1}{\left(1+\theta^{*}\right)}}$

Then, we get $\mathrm{MP}_{0}$, which is a Magnification Parameter of $T E S_{0}$.

Step3. Solve the TS-EDM model using formulas (3.1)-(3.8); then an optimal input reduction value and output increase value to reach a $\mathrm{TES}_{0}$ can be calculated.

$$
\begin{gathered}
\min \operatorname{Fr}^{x}=\sqrt{\sum_{m}\left(v_{m}^{*} x_{m o}-v_{m}^{*} d_{m o}^{x}\right)^{2}} \\
\min \operatorname{Fr}^{y}=\sqrt{\sum_{s}\left(u_{s}^{*} y_{s o}-u_{s}^{*} d_{s o}^{y}\right)^{2}} \\
\text { s.t. } \operatorname{TES}_{0}=\frac{\sum_{s} u_{s}^{*}\left(y_{s o}+d_{s o}^{y}\right)}{\sum_{m} v_{m}^{*}\left(x_{m o}-d_{m o}^{x}\right)} \\
\sum_{m} v_{m}^{*}\left(x_{m o}-d_{m o}^{x}\right)=1-M P_{0}\left(1-\theta^{*}\right) \times \frac{1}{\left(1+\theta^{*}\right)} \\
\sum_{s} u_{s}^{*}\left(y_{s o}+d_{s o}^{y}\right)=\theta^{*}+M P_{0}\left(1-\theta^{*}\right) \times \frac{\theta^{*}}{\left(1+\theta^{*}\right)} \\
x_{m o}-d_{m o}^{x} \geq 0 \\
d_{m o}^{x} \geq 0
\end{gathered}
$$




$$
d_{s o}^{y} \geq 0
$$

An illustration of the TS-EDM model is given in Figure 6.

From Figure 6, we notice that a type of $\mathrm{TES}_{0}=1.000$ is just equal to the normal $\mathrm{EDM}$ model using formulas (2.1)-(2.7). We also notice that the Non-Attainment EDM projection $\left(\theta *<\mathrm{TES}_{0}<1\right)$ does not reach the efficiency frontier, thus, this is one of the improvement goal projections to reach a $\mathrm{TES}_{0}$ lower than 1.000.

Additionally, a Super-Efficient EDM projection (TES $>>1.000$ ) offers an above 1.000 improvement plan, which is relevant in particular for DMUs that are already close to the efficiency frontier .

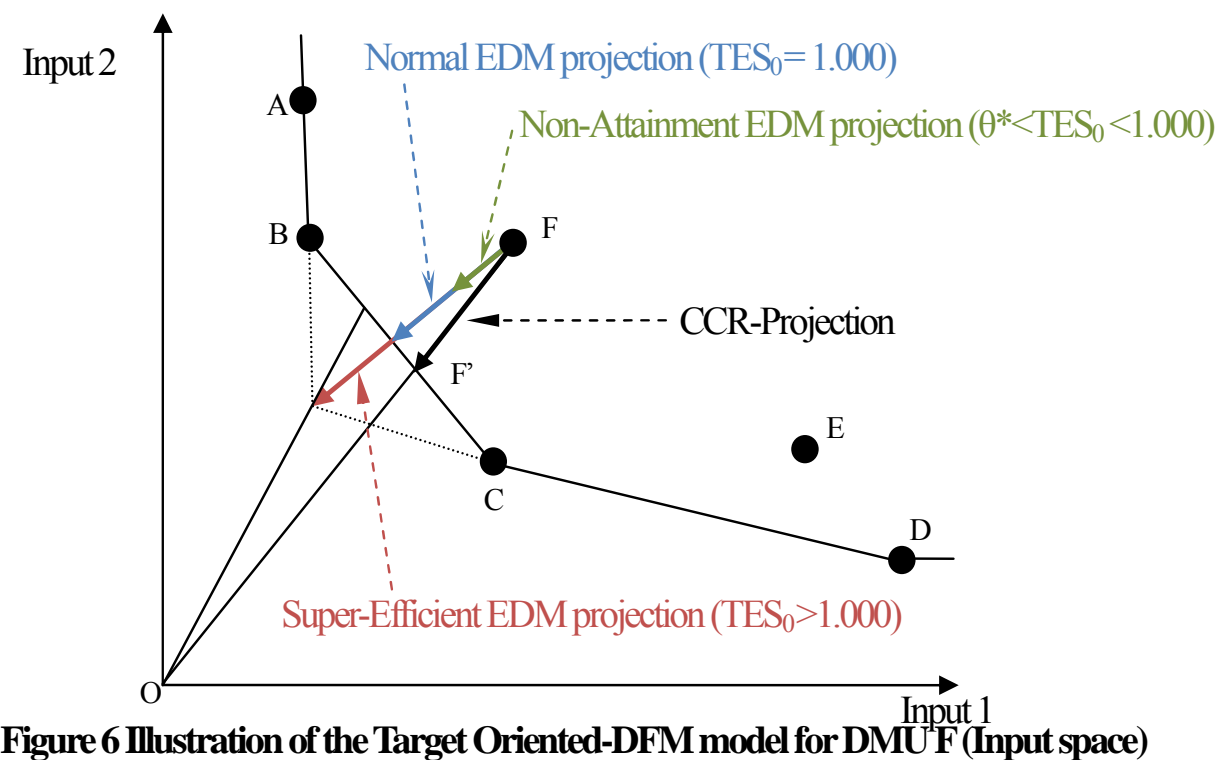

Figure 6 Illustration of the Target Oriented-DFM model for DMU F (Input space)

Figure 6 shows that the direction of the target setting is determined by the Euclidian distance model, whereas the degree to which the efficiency score is improved depends on the TES parameter set by the decision maker..The usual situation where DMUs try to improve their position incrementally will be that the $\mathrm{TES}_{0}$ parameter will be lower than 1 .

\section{An application of Target Oriented-EDM Model for Energy-Environment efficiency in Japan}

\subsection{Database and analytical framework}

We use the following inputs and outputs data for a set of 10 regions related to each of the management zones for the 10 electrical power companies in Japan (as in Figure 1). The DMUs used in our analysis are listed in Table 1 .

As shown in Table 1, we will compare an efficiency score from before the Fukushima accident (in 2010) with the efficiency score after the accident (in 2011).

Figure 7 presents the inputs and outputs considered in this analysis of regional efficiency.

Table 1A listing of DMUs

\begin{tabular}{|r|l|r|l|}
\hline No & \multicolumn{1}{|c|}{ DMUs } & DMUs \\
& (before FUKUSHIMA accident) & No & (after FUKUSHIMA accident) \\
\hline 1 & Hokkaido 2010 & 11 & Hokkaido 2011 \\
\hline
\end{tabular}




\begin{tabular}{|r|l|r|l|}
2 & Tohoku 2010 & 12 & Tohoku 2011 \\
\hline 3 & Tokyo 2010 & 13 & Tokyo 2011 \\
\hline 4 & Chubu 2010 & 14 & Chubu 2011 \\
\hline 5 & Hokuriku 2010 & 15 & Hokuriku 2011 \\
\hline 6 & Kansai 2010 & 16 & Kansai 2011 \\
\hline 7 & Chugoku 2010 & 17 & Chugoku 2011 \\
\hline 8 & Shikoku 2010 & 18 & Shikoku 2011 \\
\hline 9 & Kyushu 2010 & 19 & Kyushu 2011 \\
\hline 10 & Okinawa 2010 & 20 & Okinawa 2011 \\
\hline
\end{tabular}

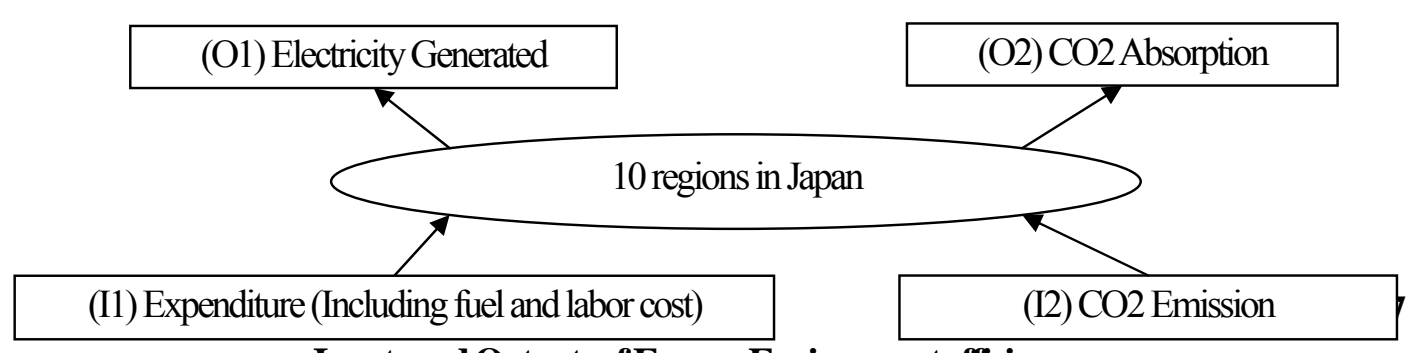

\section{Inputs and Outputs of Energy-Environment efficiency}

We consider 2 Inputs (I):

(I1) Expenditure of electricity company (Including fuel and labour cost) (million Yen/year)

(I2) $\mathrm{CO}_{2}$ Emission (after reflection of carbon credit) (10000 $\mathrm{t} /$ year)

and 2 Outputs are incorporated:

(O1) Electricity Generated (million kWh / year)

(O2) $\mathrm{CO}_{2}$ Absorption in region (Ton/ year) (2000)

Datasets (I1), (I2) and (O1) were obtained from the "electrical power industry handbook", 2010 and 2011.

The (O2) dataset is based on "Land-Use, Land Use Change, and Forestry" (IPCC, 2000) and carbon absorption basic units for needle leaf tree (artificial forest), broad-leaf tree (artificial forest), needle leaf tree (natural forest) and broad-leaf tree (natural forest) [Data source: Sugihara et al. "Carbon pool of Japanese islands", Studies in Regional Policy (Development Bank of Japan), vol.11, 2004, pp.1-49].

In our application, we first applied the Super-Efficiency CCR-I model (see Appendix A1 and A2), while then the results were used to determine the CCR-I, EDM and TS-EDM projections. Additionally, we applied the TSEDM model using Hokkaido 2010 as a reference region.

\subsection{Efficiency evaluation based on the Super-Efficiency CCR-I model}

An efficiency evaluation result for the 10 regions in 2010 and 2011(total 20 DMUs) based on the SuperEfficiency CCR-I model is presented in Figure 8.

From Figure 8, it can be seen that Hokkaido 2010 and Hokuriku 2010 are super-efficient DMUs.

On the other hand, we notice that the efficiency score of all 2011 DMUs decreases significantly compared with each of the 2010 DMUs. A reason for the decrease is definitely the adverse influence of the Fukushima problem, which meant that all regional electricity companies compensated for the electrical shortage by increased thermal power generation based on coal, oil and LNG (liquefied natural gas), which caused an increased fuel cost and a rapid rise in $\mathrm{CO}_{2}$ emissions from 2010 to 2011.

It is also noteworthy that Hokkaido deteriorated rapidly from a score of 1.403 to 0.782 . The reason for this is its heavy dependency on nuclear power generation, which was $44 \%$ in 2010, the highest level of dependency in Japan. Given the above findings, it is necessary to make an effort in efficiency improvement of the "EnergyEnvironment" balance in each region. 


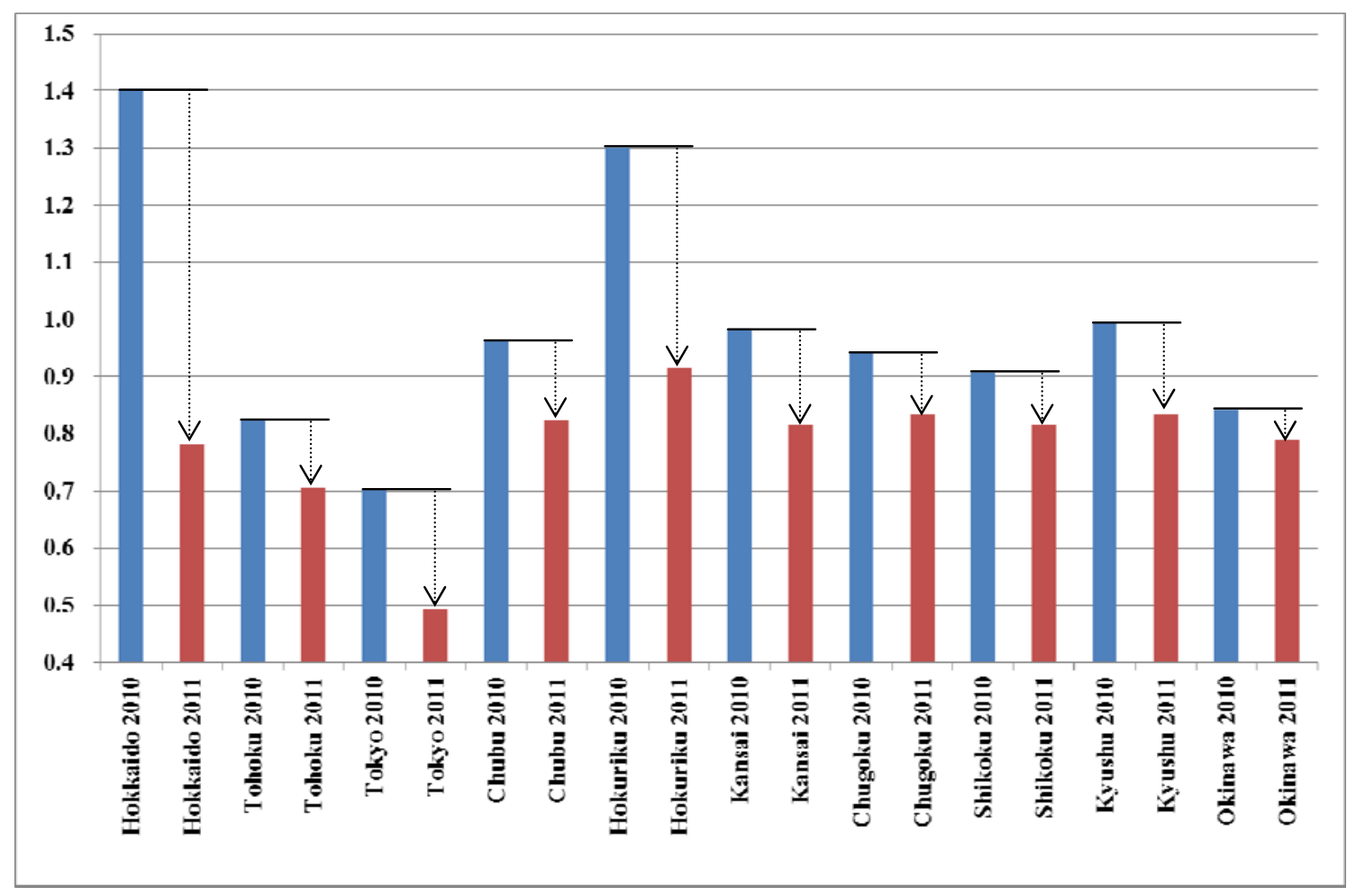

\subsection{Efficiency improvement projection based on the CCR, EDM and TS-EDM models}

The results of efficiency improvement projection based on the CCR, EDM and TS-EDM models for 2011 DMUs are presented in Table 2.

It appears that, as expected, the empirical ratios of change in the EDM projection are smaller than in the CCR projection. In Table 2, this particularly applies to Hokuriku, which is apparently a non-slack type (i.e., $s^{-* *}$ and $s^{+* *}$ are zero) region. Apart from the practicality of such a solution, the models clearly show that a different - and perhaps more efficient - solution than the standard CCR projection is available for reaching the efficiency frontier. For instance, the CCR projection shows that Tohoku should reduce its $\mathrm{CO}_{2}$ emission by $52.2 \%$ and its Expenditures by $29.5 \%$, in order to become efficient. On the other hand, the EDM results show that a reduction in $\mathrm{CO}_{2}$ emission of $45.9 \%$ and Expenditures by $17.3 \%$, together with an increase in the Electricity Generated of $17.7 \%$ is required to become efficient.

In the case of the TS-EDM model, we set a TES target for each 2011 DMU in comparison to the -superefficiency score in 2010 before the Fukushima disaster as represented in Fig. 8. For example for Tohuku this score was 0.822 in 2010. To achieve this score using the Euclidian distance approach, a reduction in Expenditures of $7.7 \%$ and an increase in Electricity Generated of $7.9 \%$ are required. It thus appears that the TS-EDM result is able to present a realistic efficiency-improvement plan, compared with the CCR and EDM approach for the DMUs with an efficiency score below 1 in the initial situation.

Table 2 Efficiency-improvement projection results of the CCR, EDM and PB-EDM models 


\begin{tabular}{|c|c|c|c|c|c|c|c|}
\hline & & \multirow{2}{*}{\multicolumn{2}{|c|}{$\begin{array}{l}\text { CCR model } \\
\text { Score }\left(\theta^{* *}\right)\end{array}$}} & \multirow{2}{*}{\multicolumn{2}{|c|}{$\begin{array}{c}\text { EDM model } \\
\text { Score }\left(\theta^{\star *}\right)\end{array}$}} & \multirow{2}{*}{\multicolumn{2}{|c|}{$\begin{array}{c}\text { TO-EDM model } \\
\text { Score }\left(\theta^{* *}\right) \\
\end{array}$}} \\
\hline DMU & Score & & & & & & \\
\hline $1 / 0$ & Data & Difference & $\%$ & Difference & $\%$ & Difference & $\%$ \\
\hline Hokkaido 2011 & 0.782 & \multicolumn{2}{|c|}{1.000} & \multicolumn{2}{|c|}{1.000} & 1.403 & (2010 level) \\
\hline (I)CO2 Emmision & 1560.0 & -444.3 & $-28.5 \%$ & -361.7 & $-23.2 \%$ & -252.4 & $-16.2 \%$ \\
\hline (I)Expenditure & 693347.0 & -151107.2 & $-21.8 \%$ & -84793.5 & $-12.2 \%$ & -197003.8 & $-28.4 \%$ \\
\hline (O)Electricity Generated & 36473.0 & 0.0 & $0.0 \%$ & 4668.2 & $12.8 \%$ & 10845.7 & $29.7 \%$ \\
\hline (O)CO2 Absorption & 7570713.9 & 0.0 & $0.0 \%$ & 0.0 & $0.0 \%$ & 0.0 & $0.0 \%$ \\
\hline Tohoku 2011 & 0.705 & \multicolumn{2}{|c|}{1.000} & \multicolumn{2}{|l|}{1.000} & 0.822 & (2010 level) \\
\hline (I)CO2 Emmision & 4113.0 & -2145.2 & $-52.2 \%$ & -1886.7 & $-45.9 \%$ & 0.0 & $0.0 \%$ \\
\hline (I)Expenditure & 1700908.0 & -501872.8 & $-29.5 \%$ & -294363.8 & $-17.3 \%$ & -130843.0 & $-7.7 \%$ \\
\hline (O)Electricity Generated & 82577.0 & 0.0 & $0.0 \%$ & 14607.6 & $17.7 \%$ & 6493.0 & $7.9 \%$ \\
\hline (O)CO2 Absorption & 8155474.7 & 0.0 & $0.0 \%$ & 129.5 & $0.0 \%$ & 0.0 & $0.0 \%$ \\
\hline Tokyo 2011 & 0.493 & \multicolumn{2}{|c|}{1.000} & \multicolumn{2}{|l|}{1.000} & 0.702 & (2010 level) \\
\hline (I)CO2 Emmision & 12420.0 & -6532.3 & $-52.6 \%$ & -4531.9 & $-36.5 \%$ & 0.0 & $0.0 \%$ \\
\hline (I)Expenditure & 8460237.0 & -4291032.7 & $-50.7 \%$ & -2874486.1 & $-34.0 \%$ & -1484172.3 & $-17.5 \%$ \\
\hline (O)Electricity Generated & 290814.0 & 0.0 & $0.0 \%$ & 98808.2 & $34.0 \%$ & 51017.3 & $17.5 \%$ \\
\hline (O)CO2 Absorption & 2964120.5 & 8973218.6 & $302.7 \%$ & 13029099.7 & $439.6 \%$ & 0.0 & $0.0 \%$ \\
\hline Chubu 2011 & 0.824 & \multicolumn{2}{|c|}{1.000} & \multicolumn{2}{|l|}{1.000} & 0.963 & (2010 level) \\
\hline (I)CO2 Emmision & 5992.0 & -3178.6 & $-53.1 \%$ & -2906.6 & $-48.5 \%$ & 0.0 & $0.0 \%$ \\
\hline (I)Expenditure & 2418629.0 & -426381.5 & $-17.6 \%$ & -233798.8 & $-9.7 \%$ & -188819.0 & $-7.8 \%$ \\
\hline (O)Electricity Generated & 138965.0 & 0.0 & $0.0 \%$ & 13433.2 & $9.7 \%$ & 10848.8 & $7.8 \%$ \\
\hline (O)CO2 Absorption & 3578336.6 & 2125901.6 & $59.4 \%$ & 2677390.4 & $74.8 \%$ & 0.0 & $0.0 \%$ \\
\hline Hokuriku 2011 & 0.915 & \multicolumn{2}{|c|}{1.000} & \multicolumn{2}{|l|}{1.000} & 1.302 & (2010 level) \\
\hline (I)CO2 Emmision & 1577.0 & -929.3 & $-58.9 \%$ & 0.0 & $0.0 \%$ & -818.0 & $-51.9 \%$ \\
\hline (I)Expenditure & 499630.0 & -42417.6 & $-8.5 \%$ & -22149.0 & $-4.4 \%$ & -86985.7 & $-17.4 \%$ \\
\hline (O)Electricity Generated & 31884.0 & 0.0 & $0.0 \%$ & 1426.8 & $4.5 \%$ & 5603.5 & $17.6 \%$ \\
\hline (O)CO2 Absorption & 1344240.6 & 0.0 & $0.0 \%$ & 0.0 & $0.0 \%$ & 194547.3 & $14.5 \%$ \\
\hline Kansai 2011 & 0.815 & \multicolumn{2}{|c|}{1.000} & \multicolumn{2}{|c|}{1.000} & 0.982 & (2010 level) \\
\hline (I)CO2 Emmision & 6044.0 & -2833.8 & $-46.9 \%$ & -2506.2 & $-41.5 \%$ & 0.0 & $0.0 \%$ \\
\hline (I)Expenditure & 2789925.0 & -516728.5 & $-18.5 \%$ & -284732.2 & $-10.2 \%$ & -260005.4 & $-9.3 \%$ \\
\hline (O)Electricity Generated & 158562.0 & 0.0 & $0.0 \%$ & 16182.4 & $10.2 \%$ & 14777.1 & $9.3 \%$ \\
\hline (O)CO2 Absorption & 3462163.1 & 3046493.2 & $88.0 \%$ & 3710749.1 & $107.2 \%$ & 0.0 & $0.0 \%$ \\
\hline Chugoku 2011 & 0.835 & \multicolumn{2}{|c|}{1.000} & \multicolumn{2}{|l|}{1.000} & 0.941 & (2010 level) \\
\hline (I)CO2 Emmision & 3014.0 & -1632.5 & $-54.2 \%$ & -1526.6 & $-50.7 \%$ & 0.0 & $0.0 \%$ \\
\hline (I)Expenditure & 1129978.0 & -186978.1 & $-16.6 \%$ & -101921.6 & $-9.0 \%$ & -67738.8 & $-6.0 \%$ \\
\hline (O)Electricity Generated & 65585.0 & 0.0 & $0.0 \%$ & 5987.6 & $9.1 \%$ & 3979.4 & $6.1 \%$ \\
\hline (O)CO2 Absorption & 555866.6 & 0.0 & $0.0 \%$ & 0.0 & $0.0 \%$ & 0.0 & $0.0 \%$ \\
\hline Shikoku 2011 & 0.816 & \multicolumn{2}{|c|}{1.000} & \multicolumn{2}{|l|}{1.000} & 0.909 & (2010 level) \\
\hline (I)CO2 Emmision & 1380.0 & -687.9 & $-49.9 \%$ & -630.4 & $-45.7 \%$ & 0.0 & $0.0 \%$ \\
\hline (I)Expenditure & 557732.0 & -102739.0 & $-18.4 \%$ & -56580.8 & $-10.1 \%$ & -30057.0 & $-5.4 \%$ \\
\hline (O)Electricity Generated & 31546.0 & 0.0 & $0.0 \%$ & 3249.3 & $10.3 \%$ & 1726.1 & $5.5 \%$ \\
\hline (O)CO2 Absorption & 2154668.0 & 0.0 & $0.0 \%$ & 0.0 & $0.0 \%$ & 0.0 & $0.0 \%$ \\
\hline Kyushu 2011 & 0.835 & 1.000 & & 1.000 & & 0.995 & (2010 level) \\
\hline (I)CO2 Emmision & 4300.0 & -2399.8 & $-55.8 \%$ & -2251.2 & $-52.4 \%$ & 0.0 & $0.0 \%$ \\
\hline (I)Expenditure & 1589428.0 & -261998.4 & $-16.5 \%$ & -142765.8 & $-9.0 \%$ & -138556.2 & $-8.7 \%$ \\
\hline (O)Electricity Generated & 92493.0 & 0.0 & $0.0 \%$ & 8393.4 & $9.1 \%$ & 8145.9 & $8.8 \%$ \\
\hline (O)CO2 Absorption & 1242290.3 & 0.0 & $0.0 \%$ & 0.0 & $0.0 \%$ & 0.0 & $0.0 \%$ \\
\hline Okinawa 2011 & 0.789 & 1.000 & & 1.000 & & 0.843 & (2010 level) \\
\hline (I)CO2 Emmision & 515.0 & -344.1 & $-66.8 \%$ & -324.0 & $-62.9 \%$ & 0.0 & $0.0 \%$ \\
\hline (I)Expenditure & 153266.0 & -32267.4 & $-21.1 \%$ & -18031.8 & $-11.8 \%$ & -5010.4 & $-3.3 \%$ \\
\hline (O)Electricity Generated & 8440.0 & 0.0 & $0.0 \%$ & 993.0 & $11.8 \%$ & 275.9 & $3.3 \%$ \\
\hline (O)CO2 Absorption & 144722.4 & 201722.9 & $139.4 \%$ & 242484.1 & $167.6 \%$ & 0.0 & $0.0 \%$ \\
\hline
\end{tabular}

\subsection{Efficiency improvement projection of the Target Oriented-EDM model}


In this subsection, we will use the prefecture of Hokkaido 2011 as the point of departure and present an efficiency improvement projection result based on the TS-EDM model. The 2011 efficiency value is 0.782 (see figure 8). We consider steps to improve efficiency towards 0.8, 0.9 and 1.0, and furthermore towards the 2010 super efficiency level of 1.403. The resulting input reduction values and the output increase values based on the TS-EDM model are presented in Figure 9.

These results show that if Hokkaido implements an efficiency improvement plan with a TES amounting to 0.9, a reduction in Expenditures of 7.0\% and an increase in Electricity Generated of 7.3\% are required. Furthermore, for a plan to achieve again the super efficiency level of 2010 with a TES of 1.403 , a reduction in $\mathrm{CO}_{2}$ Emission of $16.2 \%$ and in Expenditure of $28.4 \%$ and an increase in the Electricity Generated of $29.7 \%$ would be required. This underlines that the TS-EDM can be used both for the formulation of efficiency improvement policies in the short run and for more ambitious policies in the longer nun.

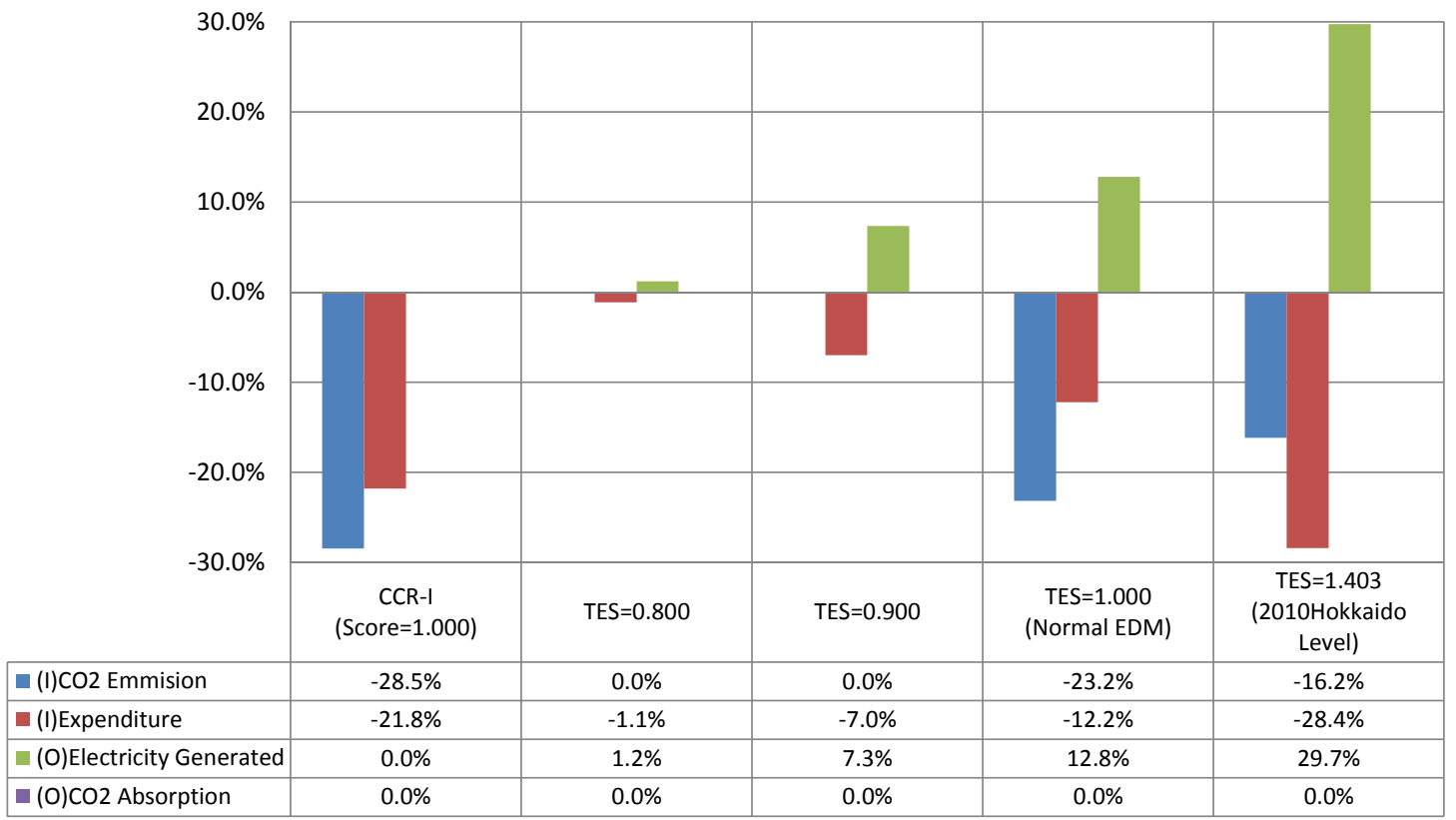

Figure 9 Efficiency improvement projection results based on the TS-EDM (Hokkaido 2011)

\section{Condusion}

In this paper, we have presented a new methodology, the TS-EDM model. Its feasibility was tested for the Japanese energy sector. The new model was adopted in realistic circumstances, based on regional efficiency improvement projections in the post-Fukushima situation in Japan.

The results appear to offer a meaningful contribution to decision making and planning for an efficiency improvement in the Energy-Environment sector for each region in Japan. These findings are mapped out in a detailed way in the present study. This new model has the potential to become a policy instrument that could offer great benefits for combined environmental-energy decision making and planning. For example, for an agreement on Energy-Environment sustainability policy, all inefficient regions have to pursue improvements in efficiency (to reach a higher target score). This framework might prompt a new concept like a regional "Kyoto Protocol” for each relevant area in Japan.

\section{References}


Anderson, P. and Petersen, N., "A Procedure for Ranking Efficient Units in Data Envelopment Analysis", Management Science, vol. 39, 1993,pp. 1261-1264.

Charnes, A., Cooper, W.W., and Rhodes, E., "Measuring the Efficiency of Decision Making Units", European Journal of Operational Research, 2, 1978, pp. 429-444.

Golany, B., "An Interactive MOLP Procedure for the Extension of DEA to Effectiveness Analysis", Journal of the Operational Research Society, 39, 1988, pp. 725-734.

Halme, M., Joro, T., Korhonen, P., Salo, S., and Wallenius, J., "A value efficiency approach to incorporating preference information in data Envelopment Analysis", Management Science, 45, (1), 1999, pp. 103-115.

Joro, T., Korhonen, P., and Wallenius, J., "Structural Comparison of Data Envelopment Analysis and Multiple Objective Linear Programming", Management Science, 44, (7), 1998, pp. 962-970.

Korhonen, P., and Siljamäki.A., "On the Use of Value Efficiency Analysis and Some Further Developments", Joumal of Productivity Analysis, 17,(1-2), 2002, pp. 49-64.

Korhonen. P., Stenfors, S., and Syrjänen. M., "Multiple objective approach as an alternative to radial projection in DEA", Journal of Productivity Analysis, 20, (20), 2003, pp. 305-321.

Lins, M. P. E., Angulo-Meza L., and Moreira da Silva, A.C., "A multi-objective approach to determine alternative targets in data envelopment analysis", Journal of Operational Research, 55, 2004, pp. 1090-1101.

Seiford, L., A Cyber-Bibliography for Data Envelopment Analysis (1978-2005), August, 2005.

Suzuki, S., Nijkamp, P., Rietveld, P., and Pels, E., "A Distance Friction Minimization Approach in Data Envelopment Analysis: A Comparative Study on Airport Efficiency", European Journal of Operational Research, vol. 207, 2010, pp.1104-1115.

Thanassoulis, E., and Dyson, R.G., "Estimating Preferred Target Input-Output Levels Using Data Envelopment Analysis," European Joumal of Operational Research, 56, 1992, pp. 80-97.

Washio, S., Yamada, S., Tanaka, T., Tanino, T., "Improvements by analyzing the efficient frontier in DEA," European Joumal of Operational Research, Vol.217, 2012, pp.173-184.

Yang, X., Morita, H., "Efficiency improvement from multiple perspectives: An application to Japanese banking industry Original Research Article,” Omega Vol.41, Issue3, 2013, pp.501-640 


\section{Appendix}

\section{A1. Outline of DEA and Efficiency Improvement Projection}

The standard Charnes et al. (1978) model (abbreviated hereafter as the CCR-input model) for a given $\mathrm{DMU}_{j}$ $(j=1, \cdots, J)$ to be evaluated in any trial $o$ (where $o$ ranges over $1,2 \ldots, J)$ may be represented as the following fractional programming $\left(F P_{o}\right)$ problem:

$$
\begin{gathered}
\left(F P_{0}\right) \quad \max _{v, u} \theta=\frac{\sum_{s} u_{s} y_{s o}}{\sum_{m} v_{m} x_{m o}} \\
\text { s.t. } \quad \frac{\sum_{s} u_{s} y_{s j}}{\sum_{m} v_{m} x_{m j}} \leq 1(j=1, \cdots, J) \\
v_{m} \geq 0, u_{s} \geq 0,
\end{gathered}
$$

where: $\theta$ represents an objective variable function (efficiency score); $x_{m j}$ is the volume of input $m(m=1, \ldots, M)$ for $\mathrm{DMU}_{\mathrm{j}}(j=1, \ldots, J) ; y_{s j}$ is the output $s(s=1, \ldots, S)$ of DMU $\mathrm{j}$; and $v_{m}$ and $u_{s}$ are the weights given to input $m$ and output $s$, respectively. Model (A.1) is often called an input-oriented CCR model, while its reciprocal (i.e., an interchange of the numerator and denominator in the objective function (A.1) with a specification as a minimisation problem under an appropriate adjustment of the constraints) is usually known as an output-oriented CCR model. Model (A.1) is obviously a fractional programming model, which may be solved stepwise by first assigning an arbitrary value to the denominator in (A.1) and then maximising the numerator.

The improvement projection $\left(\hat{x}_{o}, \hat{y}_{o}\right)$ can now be defined in (A.2) and (A.3) as:

$$
\begin{gathered}
\hat{x}_{o}=\theta^{*} x_{o}-s^{-*} ; \\
\hat{y}_{o}=y_{o}+s^{+*} .
\end{gathered}
$$

These equations indicate that the efficiency of $\left(x_{0}, y_{0}\right)$ for $\mathrm{DMU}_{\mathrm{o}}$ can be improved if the input values are reduced radially by the ratio $\theta^{*}$ and the input excesses $s^{-*}$ are eliminated(see Figure A1).

The original DEA models presented in the literature have focused on a uniform input reduction or on a uniform output increase in the efficiency-improvement projections, as shown in Figure $\mathrm{A} 1\left(\theta^{*}=\mathrm{OC} / \mathrm{OC}\right)$.

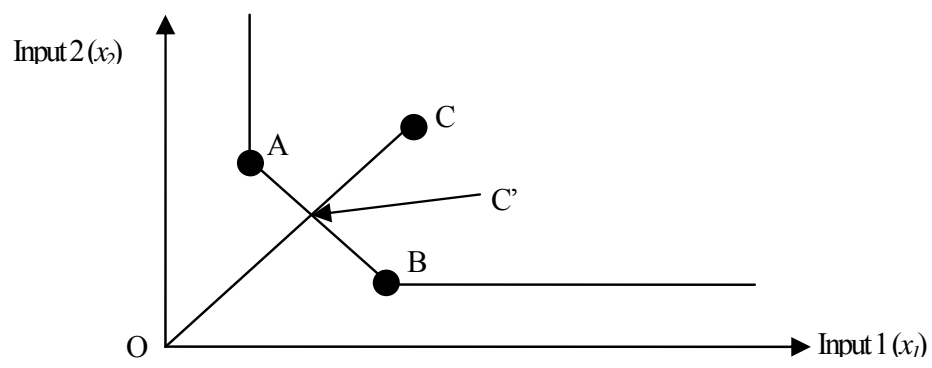

FigureA1 Illustration of oniginal DEA projection in input space 


\section{A2. Super-efficiency model}

In a standard DEA model, all efficient DMUs get the score 1 , so that there is no way to differentiate between them. This has led to focused research to discriminate between efficient DMUs, in order to arrive at a ranking, or even a numerical rating of these efficient DMUs, without affecting the results for the non-efficiency. In particular, Andersen and Petersen (1993) developed a radial Super-Efficiency model, while later on Tone $(2002,2003)$ designed a slacks-based measure (SBM) of super-efficiency in DEA. In general, a Super-Efficiency model aims to identify the relative importance of each individual efficient DMU, by designing and measuring a score for its 'degree of influence', if this efficient DMU is omitted from the efficiency frontier (or production possibility set). If this elimination really matters (i.e., if the distance from this DMU to the remaining efficiency frontier is large) and thus, the firm concerned has a high degree of influence and outperforms the other DMUs, it gets a high score (and is thus super-efficient). Therefore, for each individual DMU a new distance result is obtained, which leads to a new ranking, or even a rating of all the original efficient DMUs.

Anderson and Petersen (1993) have developed the Super-Efficiency model based on a radial projection (including a CCR model) to arrive at a ranking of all efficient DMUs. The efficiency scores from a superefficiency model are thus obtained by eliminating the data on the $\mathrm{DMU}_{o}$ to be evaluated from the solution set. For the input model, this can then result in values, which may be regarded, according to the $\mathrm{DMU}_{o}$, as a state of superefficiency. These values are then used to rank the DMUs and consequently, efficient DMUs may then obtain an efficiency score above 1.000 .

The super-efficiency model based on a CCR-I model can now be written as follows:

$$
\begin{gathered}
\min _{\theta, \lambda, S^{-}, S^{+}} \theta-e s^{-}-e s^{+} \\
\text {s.t. } \quad \theta x_{o}=\sum_{j=1, \neq o}^{J} \lambda_{j} x_{j}+s^{-} \\
y_{o}=\sum_{j=1, \neq 0}^{J} \lambda_{j} y_{j}-s^{+} \\
\lambda_{j}, s^{-}, s^{+} \geq 0
\end{gathered}
$$

where $e$ is a unit vector $(1, \ldots, 1)$, representing a utility factor for all elements. 